\title{
Differences in discriminative reaction time between elite youth football players: a comparison between age-categories \\ Diferencias en el tiempo de reacción discriminativo entre jugadores de fútbol juvenil de élite: una comparación entre categorías de edad
}

*Guilherme de Sousa Pinheiro, **Herbert Soares Bernardino, ***Israel Teoldo Costa, **Varley Teoldo Costa

*Technical University of Munich (Germany) **Universidade Federal de Minas Gerais (Brazil) ***Universidade Federal de Viçosa (Brazil)

\begin{abstract}
Background: Several factors may affect the development of a player during the sports training process. Reaction time is considered an important aspect of perceptual skills in sports and can potentially affect football performance. During the maturation process of a player there may be changes in the cognitive skills, in addition to changes in the training levels that this player is submitted to. The aim of this study is to compare the discriminative reaction time (DRT) in elite young football players between categories U-15 and U-17. Methods: Participants were 236 elite Brazilian young male football players from categories U-15 ( $\mathrm{n}=139, M_{\text {age }}=14.21, S D=0.66$ years $)$ and U-17 $\left(\mathrm{n}=97, M_{\text {age }}=17.99, S D=0.48\right.$ years $)$. The Reaction Test (S5 version), provided by the Vienna Test System SPORTS ${ }^{\circledR}$ (VTS) was applied. Results: statistically significant difference was found in the DRT $(p=.04)$ between football players of categories U-15 and U-17. U-17 players faster $(M=526 \mathrm{~ms}$, sd $=65.30)$ when compared to the U-15 players $(M=543 \mathrm{~ms}$, sd $=62.40)$, however with a small effect size (.13). Conclusion: Elite football players in the U17 category have better DRT values than players in the U15 category.
\end{abstract}

Keywords: reaction time, youth football players, cognitive capacity, sports training.

Resumen. Introducción: Varios factores pueden afectar al desarrollo de un jugador durante el proceso de formación deportiva. El tiempo de reacción se considera un aspecto importante de las habilidades perceptivas en el deporte y puede afectar potencialmente al rendimiento futbolístico. Durante el proceso de maduración de un jugador pueden producirse cambios en las habilidades cognitivas, además de cambios en los niveles de entrenamiento a los que se somete este jugador. El objetivo de este estudio es comparar el tiempo de reacción discriminativo en jóvenes futbolistas de élite entre las categorías sub-15 y sub17. Métodos: Los participantes fueron 236 jóvenes futbolistas brasileños de élite de las categorías Sub-15 ( $\mathrm{n}=139$, Edad media $=14,21, \mathrm{sd}=0,66$ años) y Sub-17 $(\mathrm{n}=97$, Edad media $=17,99, \mathrm{sd}=0,48$ años). Se aplicó el Test de Reacción (versión S5), proporcionado por el Vienna Test System SPORTS® (VTS). Resultados: se encontraron diferencias estadísticamente significativas en el DRT $(\mathrm{p}=.04)$ entre los futbolistas de las categorías sub-15 y sub-17. Los jugadores sub-17 fueron más rápidos $(\mathrm{M}=526 \mathrm{~ms}$, sd =65,30) en comparación con los jugadores sub-15 $(\mathrm{M}=543 \mathrm{~ms}$, sd =62,40), aunque con un tamaño del efecto pequeño (.13). Conclusión: Los jugadores de fútbol de élite de la categoría sub17 tienen mejores valores de tiempo de reacción discriminativo que los jugadores de la categoría sub15.

Palabras clave: tiempo de reacción, futbolistas juveniles, capacidad cognitiva, entrenamiento deportivo.

\section{Introduction}

Reaction time (RT) is a variable capable of influencing sports development (Gierczuk, et al., 2017; Johne et al., 2013; Parma et al., 2017). RT can be defined as the time that elapses from when a stimulus appears until a response is given and is considered a good measure to assess the capacity of the cognitive system to process information (Jensen, 2006; Kuang, 2017). This variable

Fecha recepción: 02-03-21. Fecha de aceptación: 02-09-21

Guilherme de Sousa Pinheiro

guilherme.gsp11@hotmail.com can be described into three types: (1) Simple reaction time (SRT): here there is one stimulus and one response; (2) Discriminative reaction time (DRT): here there are some stimuli that should be responded to and other that should not get a response; and (3) Choice reaction time (CRT): here there are multiple stimuli and multiple responses. DRT and CRT are considered complex RT due to the increased number of stimuli and response options (Magill and Anderson, 2014).

In adversary or collective sports, such as football, RT is a key component of performance, as players are required to make quick decisions to be successful in their actions (Sousa et al., 2021; Ruschel et al., 2011; Mudric et al., 2015; van de Water et al., 2017). 
Players must react to the changing environment in the shortest possible time, and quickly adapt to tactical situations, to gain an advantage and score (ElferinkGemser et al. 2004; Delignières et al., 1994). Players have countless possibilities for correct decision-making at the time when they are with and without the ball (Borges, 2017; Roca et al., 2012; Vaeyens, et al., 2007). For instance, DRT is the type of reaction that occurs more often given the demands of the match. That responsiveness in football is one of the key abilities that determine the technical and tactical skills (Stepinski and Debicka, 2004). Thus, for talent promotion, analyses of perceptual-cognitive skills might be of special interest and could deliver several approaches for practical applications (Schumacher et al., 2021).

Several factors can influence the RT, such as fatigue, physical condition, experience, motivation, gender, age, or dominance of the body member with which one responds (Baayen and Milin, 2010). Research has shown that sports practice would be related to improvement in RT (Jain et al., 2015; Okubo et al., 2017; van de Water et al., 2017; Walton et al., 2018). During the progression in the sports career, youth players start competing in more dynamic matches, with increased cognitive demands. Players in the U-15 category are included in more complex training programs compared to the younger categories. Training sessions usually occur 5 to 6 times a week, and the participation in state and national competitions begins. In the U- 17 category there is a significant increase in competitive character, with an increase in pressure for performance. The weekly training sessions reach 7-8 times a week, and participations in national and international competitions are more frequent. There is a specialization of the trainings by positions and a higher demand for understanding of tactical principles of the match (Borges et al., 2017; Marques and Samulski, 2009).

To improve the performance of football players, a large amount of data is produced (Pinheiro et al., 2021). The literature has highlighted the importance of RT for success in football (Wojciech et al., 2021). Previous research showed that professional players have a better complex reaction time which suggests that this may be a parametre used to identify talents among young football players (Hirose, 2011). Huijgen et al. (2015) showed that cognitive abilities depend on the level of training of young footballers. The measurement of the response time was also performed on young players of the German $1^{\text {st }}$ league who were divided into age categories U12, U13, U17 and U19. The study shows that with age reaction time improves (Beavan et al., 2019). Vanttinen et al. (2010) examined an improvement of response time with age in young footballers' group. Hirose et al. (2002) analyzed changes of the response time due to chronological and skeletal age in the group of football players between the age of 10 to 15 where reaction time improves with age. However, there is a lack of evidence in the literature about DRT changes among different age groups in Brazilian elite players.

Considered that football is one of the most practiced sports in the world (Carbonell et al., 2021), research is necessary to evaluate the behavior of this variable, since during the sports development it is observed a maturational and physical change in individuals in the age range of 15 to 17 years (Malina et al., 2015), as well as technical-tactical (Mendez-Villanueva et al., 2013) and cognitive changes (Huijgen et al., 2015). To clarify the mechanisms of underlying perceptual-cognitive expertise as RT, it is important to identify the specific elite performance within the different age groups. Therefore, the objective of this study is to compare the DRT in elite young football players between categories U-15 and U-17.

\section{Materials and methods}

\section{Participants}

Participated in the study 236 young Brazilian elite male players. The players were from 3 teams of the $1^{\text {st }}$ division of the Brazilian Championship. The participants were divided into two groups, called categories: U-15 ( $\mathrm{n}=139, M_{\mathrm{age}}=14.21, \mathrm{SD}=0.66$ years; beginning of the football formal practice $M=6.85, S D=2.15$ years old; body mass $M=61.80, S D=7.40 \mathrm{Kg}$; height $M=$ $172.70, S D=7.10 \mathrm{~cm})$ and U-17 $\left(\mathrm{n}=97, M_{\text {age }}=17.99\right.$, $S D=0.48$ years; beginning of the formal football practice $M=6.90, S D=1.85$ years old; body mass $M=$ 68.90, $S D=7.40 \mathrm{Kg}$; height $M=177.50, S D=7.38$ $\mathrm{cm})$.

A letter of acceptance was obtained from the football clubs in agreement with the research procedures. The anonymity of the participants was preserved throughout the process. The data were only involved in this study after the agreement of the participants. All research procedures were conducted according to the norms established by the National Health Council Resolution (466/2012) and the Declaration of Helsinki for research with humans. The project was approved by the Human Research Ethics Committee (CAAE60155916.3.0000.5149). 


\section{Instrument}

The computerized reaction test ( $\mathrm{S} 5$ version) included in the Vienna Test System SPORTS ${ }^{\circledR}$ (VTS) was used to measure players DRT (Schuhfried et al., 2001, Prieler, 2008). The VTS is a computerized system developed to objectively assess cognitive skills (Hackfort et al., 2009; Ong, 2015) in football (Andrade et al., 2021, Costa et al., 2020; Penna et al., 2015) and in other Olympic (Ferreira et al., 2017; Ong, 2015;) and Paralympic sports (Parma et al 2015). Detailed description and reliability are previous given (Schumacher et al., 2019; Ferreira et al., 2021).

\section{Procedure}

The computerized reaction test (version S5) was applied before the beginning of the training sessions, with the players in resting condition. The players were individually evaluated in a room without external interventions. During the test they were always accompanied by the same researcher properly trained and qualified to apply the test. The test lasts 5 minutes and it starts with a familiarization process with duration of 1 minute. It consists of a task in the notebook display during which different visual stimuli (yellow and red colors) and sound (bass sound) are presented. When the two specific stimuli appeared on the monitor (yellow and red colors together or yellow color and bass sound together) the player should take his finger off the rest button and use the same finger to press the reaction button as soon as possible. In case other stimuli showed up the player was advised to stay with his finger on the rest key. The result is given by the average of DRT to the pressed stimuli time between the beginning of the stimulus until the release of the rest key expressed in milliseconds (ms). A 14"screen computer, Asus ${ }^{\circledR}$ brand model K450 and amd ${ }^{\mathbb{R}}$ Vision8 connected to the VTS equipment was used (Ferreira et al., 2021; Costa et al., 2020; Ferreira et al., 2017; Johne et al., 2013; Penna et al., 2015; Schuhfried, 2001).

\section{Statistical analysis}

The data normality was confirmed using the Kolmogorov-Smirnov test. To compare the average of DRT between categories U-15 and U-17 a T Student's test was used. The effect size was calculated in accordance with the proposal of Cohen (1992), to compare the magnitude of the difference between the categories U15 and U-17. The level of significance was set at $p<$ .05. Statistical analyzes were performed in the SPSS ${ }^{\circledR}$ for Windows ${ }^{\circledR}$ (IBM Corp. Released 2013. IBM SPSS Statistics for Windows, Version 22.0. Armonk, NY: IBM Corp).

\section{Results}

Significant differences were found in DRT $(p=.04)$ when comparing the elite young football players of categories U-15 and U-17 (Graph 1). The football players of category U-17 were faster $(M=526 \mathrm{~ms}$, sd $=65.30)$ when compared to the players of U-15 ( $M=543 \mathrm{~ms}$, sd $=62.40)$, with a small effect size is (.13).

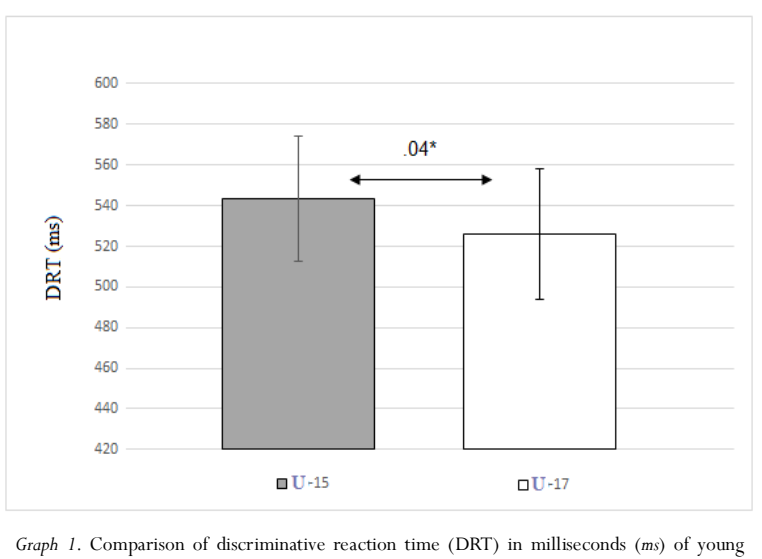

football players between categories $\mathrm{U}-15$ and $\mathrm{U}-17 .{ }^{*} p<.05$ between the groups.

\section{Discussion}

The objective of this study was to compare the DRT in elite young football players between age-categories U-15 and U-17. The results showed that there were statistically significant differences in DRT performance between U-17 and U-15 elite players $(M=543, S D=$ $62.40 \mathrm{~ms} ; M=526, S D=65.30)$, however with a small effect size (.13). The small effect size found in the present study, may somewhat corroborate previous research (Wojciech et al., 2021). That research showed the best level of cognitive abilities in the study was shown in the age group of 14-15 and 16 years old, where both groups had similar results (Wojciech et al., 2021).

In the present study, the young group (U-15) presented lower results, as well as found by Wojciech et al. (2021). These results could indicate that with age, the level of cognitive abilities develops until around 14 years old. Multiple regression analysis shows that age influences every psychomotor test except simple reaction time (Wojciech et al., 2021). Similar conclusions were obtained during the studies conducted by Beavan et al. (2019) where the reaction time of young footballers was related to age. The improvement of complex reaction time with age in young footballers was confirmed in the study of Hirose et al. (2002) where the complex reaction time decreased to the age of 14 .

The present finding contrasts with the results of Johne et al. (2013), which investigated in a different sport 
DRT using the same Reaction Test (S5 version) in female fencers' players in different categories. Those authors concluded that older players had faster DRT when compared with the younger ones. Lex et al. (2015) conducted a study with to evaluate the decision making ability in football players with longer and shorter practice time. It was found that players with longer practice time had a better performance in DRT when compared to players with shorter practice time, concluding that players with longer practice time had faster tactic decision making. In both individual and team sports, it is noted that players with more training experience, with advanced level of biological and cognitive maturation, presented better results of DRT.

Although the result of the present study has small effect size between the groups evaluated, previous studies have indicated that the biological and cognitive maturation factors associated with the practice time (i.e., years of systematic training) may influence the DRT development (Huijgen et al., 2015; Lex et al. 2015; Malina et al., 2015; Penna et al., 2015). Notwithstanding isolated DRT training is not common in football, this variable is integrated with the technical, tactical, and physical demands that are inherent in football matches and training (Roca et al., 2012; Zisi et al., 2003). The importance of decision-making skill cannot be understated, as an incorrect decision can potentially have a detrimental impact on the game result, and in the final analysis possibly club revenue (Kittel et al., 2019; Larkin et al., 2011).

During the constantly changing environment of a football match, players are processing information (e.g., from the ball, teammates, and the opposition) and subsequently making decisions also influenced by team tactics, technical ability and physical capacity (Reily et al., 2000; Williams, 2000). The high technical and tactical demands of football match play with the frequent pressure to meet internal and external expectations may well place a mental demand on an elite football player. It is noted that team sport performance is more cognitively demanding than several physical activities (Thompson et al., 2019), which demonstrates the importance of DRT during training process (Zisi et al., 2003).

In order to understand if RT can be a variable that discriminates the talent in football, Hirose (2011) in a prospective study used another type of complex RT which is the CRT with the purpose to identify the performance level in football players. The players with better CRT reached higher competitive levels in Japan, the players who had worse results in CRT remained at amateur levels, concluding that CRT is a predictor variable for the success or failure in a career. Studies involving other types of RT in football had presented similar results. In the study of Ando et al. (2001), the authors compared the RT between university players and non-players. The results showed that the university players are faster when compared to non-players. Similar results were found in the study of Montes-Mico et al. (2000) with the objective to compare young football players and non-players, concluding that the RT is a variable which differentiates these subjects.

As football requires decision making frequently due to a variety of stimuli and response options, this makes us to hypothesize that the DRT is more specific to cognitively assess football players, according to the characteristics of the decision-making process in this sport (Magill and Anderson, 2014; Vaeyens et al., 2007; Zisi et al., 2003). The processes associated with the fast response selection and correct decision making can play an important role in the football player's formation (Zisi et al., 2003). The faster the DRT speed, the longer the player will have to perform the movement and this can mean a competitive advantage during the trainings and matches (Vaeyens et al., 2007; Roca et al., 2012).

Due to the difficulty of access to elite players in Brazil, and the limited logistics provided by clubs, this study has limitations. It was not possible to apply different tests related to reaction time or to evaluate other categories. Despite of these limitations, this study presents unpublished and relevant results that suggests no differences in the DRT in football elite players between categories U-15 and U-17. The study provides useful information for coaches and physical trainers and aims to arouse the attention of these professionals for the specific trainings elaboration that may potentiate the DRT in young football players. Given the specificity of this type of RT, further research is needed to investigate the relationship of ecological and laboratory experiments. This kind of analysis would allow to understand how the DRT interfered in the decision making process and consequently on athletic performance.

\section{Conclusions}

The present study delivers new findings about DRT performance of Brazilian elite young football players. Elite football players in the U17 category have better DRT values than players in the U15 category. 
Aforementioned results might indicate that a better performance in DRT could be age-related.

\section{References}

Andrade,M.O.C.A; Costa,V.T.; García-Calvo,T.; Figueiredo,A.; Teoldo,I. (2021) Peripheral perception as discriminantfactor of tactical behaviour efficiency of young soccer players. International Journal of Sport and Exercise Psychology, doi: 10.1080/ 1612197X.2021.1948588

Ando, S., Kida, N., and Oda, S. (2001). Central and peripheral visual reaction time of soccer players and nonathletes. Perceptual and Motor Skills, doi:10.2466/pms.2001.92.3.786

Baayen, R. H., and Milin, P. (2010). Analyzing reaction times. International Journal of Psychological Research, doi: 10.21500/20112084.807

Beavan,A.F.;Spielmann,J.;Mayer,J.;Skorski,S.;Meyer,T.;Fransen, J. (2019).Age-related differences in executive functions within high-level youth soccer players. Brazilian Journal of Motor Behavior; 13, 2:64-75.

Borges, P. H., Andrade, M. O. C., Rechenchosky, L., Teoldo, I., Teixeira, D., and Rinaldi, W. (2017). Tactical performance, anthropometry and physical fitness in young soccer players: A comparision between diferente maturational groups. Journal of Physical Education and Sport, doi:10.4025/ jphyseduc.v28i1.2826

Carbonell Bernal, N., Hernández-Prados, M., R. Sarmiento, B., González Castellón,E.,Aguaded Gómez,M., \& ÁlvarezNúñez, J. (2021). Executive functions and football performance. Design and evaluation of an intervention program. Retos, 42, 306-315. https://doi.org/10.47197/retos.v42i0.86684

Cohen, J.(1992). A power primer. Psychological Bulletin, 112, 155. doi:10.1037/0033-2909.112.1.155

Costa,V.T.;Moreira, L.;Costa,I.T.;Paúna,D.M.;Malloy-diniz,L.F. (2020). Comparison of the attention of basic football athletes per category (in Portuguese). Brazilian Journal of Sport Psychology, 10, 33-47.

Delignières, D.; Brisswalter, J.; Legros, P. (1994). Influence of physical exercise on choice reaction time in sports experts: The mediating role of resource allocation. Journal of Human Movement Studies, 27, 173-188.

Elferink-Gemser, M.; Visscher, C.; Richart, H.; Lemmink, K. (2004) Development of the tactical skillsinventory for sports. Perceptual and Motor Skills, 99, 883-895.

Ferreira, T.V.; Costa, I.T.; Pinheiro, G.S.; Albuquerque, M.R.; COSTA,V.T. (2021). Are there gender differences in reactive stress tolerance levels of Brazilian judo athletes? Ido Movement for Culture.Journal of Martial ArtsAnthropology, 21,2934, doi: 10.14589/ido.21.3.5.

Ferreira,T.V.;Noce,F.;Costa,I.T.;Vieira,M.V.; Costa,V.T.(2017).Is there a difference by sex in simple reaction time andimpulsivity in junior Brazilian judo team athletes? Archives of budo science of martial arts and extreme sports, 13, 111-118.

Gierczuk,D., Lyakh,V., Sadowski, J., and Bujak, Z. (2017). Speed of reaction and Fighting effectiveness in elite Greco-Roman Wrestles. Perceptual and Motor Skills, 124, 200-213. doi: 10.1177/0031512516672126

Pinheiro, G.S., Nascimento,V.B., Dicks, M., Costa,V.T.and Lames, M. (2021). Design andValidation of an Observational System for Penalty Kick Analysis in Football (OSPAF). Frontiers in Psychology. 12:661179. doi: 10.3389/fpsyg.2021.661179

Hackfort, D., Kilgallen, C., and Hao, L. (2009).The action theorybasedmental testand training system. In: Hung,T., Lidor, R., an Hackfort, D. Psychology of Sport Excellence:International Perspectives on Sport an Exercise Psychology (pp. 15-24). Morgantown,WV: Fitness InformationTechnology.

Hao Ong, N. C. (2015).The use of theViennaTest System in sport psychology research:A review. International Review of Sport and Exercise Psychology, 8, 204-223. doi:10.1080/ 1750984X.2015.1061581

Hirose, N. (2011). Prediction of talent in youth soccer players: prospective study over 4-6 years. Football Science, 8, 1-7.

Hirose, N.; Hirano, A.; Fukubayashi, T. (2002). Cross-sectional change in reaction time and stepping ability estimated from skeletal and chronological age in adolescent soccer players. Japanese Journal of Physical Fitness and Sports Medicine, 51, 299306.

Huijgen, B. C., Leemhuis,S., Kok, N.M.,Verburgh, L., Oosterlaan, J., Elferink-Gemser,M.T., andVisscher, C. (2015). Cognitive functions in elite and sub-elite youth soccer players aged 13 to 17 years. PloS One, 10(12), e0144580. doi:10.1371/ journal.pone. 0144580

Jain, A., Bansal, R., Kumar, A., and Singh, K. D. (2015). A comparative study of visual and auditory reaction times on the basis of gender and physical activity levels of medical first year students. International Journal of Applied and Basic Medical Research. 5, 124-127. doi: 10.4103/2229-516X.157168

Jensen,A. (2006). Cloking the Mind:Mental Chronometry and Individual Differences. Amsterdam: Elsevier.

Johne,M.,Poliszczuk,T., Poliszczuk,D., and Da'browska-Perzyna, A. (2013). Asymmetry of complex reaction time in female épée fencers of different sports classes. Polish Journal of Sport andTourism, 20,25-29. doi:10.2478/pjst-2013-0003

Kittel, A.; Elsworthy, N.; Spittle, M. (2019). Incorporating perceptual decision-making trainingintohigh-intensityinterval training for Australian football umpires. Journal of Sports Sciences, doi: $10.1080 / 02640414.2018 .1480257$

Kuang, S. (2017). Is reaction time an index of white matter connectivity during training? Cognitive Neuroscience. 8, 126128. doi: 10.1080/17588928.2016.1205575

Larkin, P., Berry, J., Dawson, B., \& Lay, B. (2011). Perceptual and decision making skills of Australian football umpires. International Journal of Performance Analysis in Sport, 11(3), 427437

Lex,H., Essig, K., Knoblauch,A., and Schack,T. (2015). Cognitive 
representations and cognitive processing of team-specific tactics in soccer. PloS One, 10(2), e0118219. doi:10.1371/ journal.pone.0118219

Magill, R.A., andAnderson, D. I. (2014). Motor learning and control: Concepts and applications (10th ed.). NewYork: McGraw-Hill.

Malina, R. M., Rogol,A. D., Cumming, S. P., Silva, M. J. C., and Figueiredo,A.J.(2015). Biological maturation of youthathletes: assessment and implications. British Journal of Sports Medicine, 49, 852-859. doi:10.1136/bjsports-2015-094623

Marques, M. P., and Samulski, D.M. (2009).Analysis of the sports career of young football athletes in the transition from the amateur to the professional phase: schooling, initiation, social and family context and career planning (in Portuguese). Brazilian Journal of Physical Education and Sport, 23, 103-119. doi:10.1590/S1807-55092009000200002

Mendez-Villanueva,A., Buchheit, M., Simpson, B., and Bourdon, P. C. (2013). Match play intensity distribution in youth soccer. International Journal of Sports Medicine, 34, 101-110. doi:10.1055/s-0032-1306323

Montes-Mico, R., Bueno, I., Candel, J., and Pons, A. M. (2000). Eye-hand and eye-foot visual reaction times of young soccer players. Optometry, 71(12), 775-780.

Mudric, M., Cuk, I., Nedeljkovic, A., Jovanovic, S., and Jaric, S. (2015). Evaluation of Video-based method for the measurement of reaction time in specific sport situation. International Journal of Performance Analysis in Sport, 15, 1077-1089. doi: 10.1080/24748668.2015.11868852

Okubo, Y., Schoene, D., and Lord, S. R. (2017). Step training improves reaction time, gait and balance and reduces falls in older people: a systematic review and meta-analysis. British Journal of Sports Medicine, 51, 586-593. doi: 10.1136/bjsports2015-095452

Parma, J. O., Costa, V.T., Andrade, A. G. P. D., Cavalcante, G., Hackfort, D., and Noce, F. (2017). Relation of personality traits and decision-making in wheelchair tennis players. International Journal of Sport and Exercise Psychology, 15, 1-12. doi:10.1080/1612197X.2016.1275742

Penna,E.M. P., Mello, M.T., Ferreira, R. M., Moraes, L. C. C.A., and Costa,V.T.(2015). Relative age effect on the reaction time of soccer players under 13 years old. Revista Motriz, 21, 194199. doi:10.1590/S1980-65742015000200010

Prieler, J. (2008). Manual RT - Reactiontest (31 th version). Mödling: Schufried.

Reilly, T., Williams, A. M., Nevill, A., and Franks, A. (2000). A multidisciplinary approach to talent identification in soccer. Journal of Sports Sciences, 18, 695-702. doi:10.1080/ 02640410050120078

Roca,A.,Williams,A. M., and Ford, P.R. (2012). Developmental activities and the acquisition of superior anticipation and decision making in soccer players. Journal of Sports Sciences, 30, 1643 1652. doi:10.1080/02640414.2012.701761

Ruschel, C., Haupenthal, A., Hubert, M., Fontana, H. B., Pereira, S. M., and Roesler,H. (2011). Simple reaction time of football players of different categories and positions (in Portuguese). Revista Motricidade, 7(4), 73-82.

Schuhfried, G. (2001). Sport psychology. Sport test battery for diagnostics and training (Mödling, Österreich). Retrieved from: https: / / www.schuhfried.com/test/RT

Schumacher N, Reer R and Braumann K-M (2020) On-Field Perceptual-CognitiveTraining Improves Peripheral Reaction in Soccer:A ControlledTrial. Frontiers in Psychology, 11:1948. doi: 10.3389/fpsyg.2020.01948

Sousa, H., Gouveia, Élvio, Marques, A., Sarmento, H., Lopes, H., \& Ihle,A. (2021). The effect of balanced versus unbalanced football small-sided games on decision-making in youth football players. Retos, 42, 744-749. https://doi.org/ 10.47197/retos.v42i0.88052

Stepinski, M .; Debicka, J. Comparison of the reaction time of the lower and upper end of footballers and people not in training; Books. Scientific Research of the Institute of Physical Culture; University of Szczecin: Szczecin, Poland, 2004; Volume21.

Thompson, C. J., Fransen, J., Skorski, S., Smith, M. R., Meyer,T., Barrett, S., \& Coutts,A.J. (2019). Mental Fatigue in Football:Is it Time to Shift the Goalposts? An Evaluation of the Current Methodology. Sports medicine (Auckland, N.Z.), 49(2), 177183. https://doi.org/10.1007/s40279-018-1016-z

Vaeyens,R.,Lenoir,M.,Williams,A. M., Mazyn,L., andPhilippaerts, R. M. (2007). The effects of task constraints on visual search behavior and decision-making skill in youth soccer players. Journal of Sport \& Exercise Psychology, 29, 147-169. doi:10.1123/ jsep.29.2.147

van deWater,T., Huijgen, B., Faber, I., and Elferink-Gemser, M. (2017).Assessing cognitive performance in badminton players: a reproducibility and validity study. Journal of Human Kinetics. 55, 149-159. doi: 10.1515/hukin-2017-0014

Vänttinen,T., Blomqvist, M., Luhtanen,P., and Häkkinen, K. (2010). Effects of age and soccer expertise on general tests of perceptual and motor performance among adolescent soccer players. Perceptual and Motor Skills, 110, 675-692. doi:10.2466/ pms.110.3.675-692

Zisi,V., Derri,V., and Hatzitaki,V. (2003). Role of perceptual and motor abilities in instep-kicking performance of young soccer players. Perceptual and Motor Skills, 96, 625-636. doi:10.2466/ pms.2003.96.2.625

Walton, C. C., Keegan, R. J., Martin, M., and Hallock, H. (2018). The potential role for cognitive training in sport: more research needed. Frontiers in Psychology, 9:1121. doi: 10.3389/ fpsyg. 2018.01121

Williams AM. Perceptual skill in soccer: implications for talent identification and development. Journal of Sports Sciences. 2000;18(9):737-50

Wojciech, P.;Maciej,S.;Mariusz,P.;Janusz,Z.; Polak, K.;Huzarski, M.; Krzysztof, P. (2021) Characteristics of CognitiveAbilities among Youths Practicing Football. International Journal of Environmental Research and Public Health, 18, 1371. https: / / doi.org/10.3390/ ijerph18041371 